\title{
Electrophysiological evidence for parallel and serial processing during visual search
}

\author{
STEVEN J. LUCK and STEVEN A. HILLYARD \\ University of California, San Diego, La Jolla, California
}

\begin{abstract}
Event-related potentials were recorded from young adults during a visual search task in order to evaluate parallel and serial models of visual processing in the context of Treisman's feature integration theory. Parallel and serial search strategies were produced by the use of feature-present and feature-absent targets, respectively. In the feature-absent condition, the slopes of the functions relating reaction time and latency of the P3 component to set size were essentially identical, indicating that the longer reaction times observed for larger set sizes can be accounted for solely by changes in stimulus identification and classification time, rather than changes in postperceptual processing stages. In addition, the amplitude of the P3 wave on target-present trials in this condition increased with set size and was greater when the preceding trial contained a target, whereas P3 activity was minimal on target-absent trials. These effects are consistent with the serial self-terminating search model and appear to contradict parallel processing accounts of attention-demanding visual search performance, at least for a subset of search paradigms. Differences in ERP scalp distributions further suggested that different physiological processes are utilized for the detection of feature presence and absence.
\end{abstract}

Several recent theories of visual perception have proposed the existence of two distinct processing stages-an early stage that extracts simple features, and a later stage that identifies objects or conjunctions of features (see, e.g., Julesz, 1984; Marr, 1982; Neisser, 1967; Ullman, 1984). In a series of papers, Treisman and her colleagues have presented a detailed feature integration theory incorporating this dichotomy (Treisman, 1985; Treisman \& Gelade, 1980; Treisman \& Gormican, 1988). Feature integration theory proposes that the early, preattentive stage of processing can discriminate the identity of simple features in parallel, and that a serial, attentive process is required to localize features and conjoin them together to form objects.

Much of the evidence for this theory comes from visual search tasks, in which subjects must decide whether or not a target item is present in an array of distractor items. According to feature integration theory, a target possessing a simple feature that is absent from the distractors can be detected preattentively, and detection latency for such a target will therefore be independent of the number of items in the array (the set size). If no elementary feature

This work was supported by grants from NINCDS (NS17778) and NIMH (MH-25594), by ONR Contract NO0014-89-J-1806, and by an NSF Graduate Fellowship to the first author. A brief report of this experiment was presented at the twenty-eighth annual meeting of the Society for Psychophysiological Research, October 1988. We wish to thank Marty Woldorff and Ron Mangun for helpful discussions of this research, and Jim Hoffman and an anonymous reviewer for their comments on the manuscript. Send correspondence to Steven J. Luck, Department of Neurosciences, M-008, University of California, San Diego, La Jolla, CA 92093-0608. differentiates the target and distractors, however, then the items must be scanned individually in serial by the attentive processing stage, such that target detection latency increases linearly with set size. Since the search terminates upon detection of a target, only half of the items need to be scanned on the average for positive (target-present) trials; thus, the ratio of the slopes for negative versus positive trials should approximate 2:1. It has indeed been found in numerous studies that the search for the presence of a simple feature is independent of set size, whereas the search for a conjunction of features is not (see, e.g., Bergen \& Julesz, 1983; Egeth, Virzi, \& Garbart, 1984; Nakayama \& Silverman, 1986; Treisman \& Gelade, 1980; Wolfe \& Franzel, 1988).

The interpretation of these visual search results remains controversial, however. For example, feature integration theory states that the effect of set size on detection latency for conjunction targets is due to the serial repetition of a perceptual process. However, this effect could also be explained by postperceptual processes or capacity limitations within a parallel processing system (Farell, 1984; Pashler \& Badgio, 1987). In the case of simple feature targets, Treisman and her colleagues have proposed that set size has no effect on reaction time because features can be detected in parallel without the use of focal attention (Treisman, 1985; Treisman \& Gelade, 1980; Treisman $\&$ Souther, 1985). Other theories, however, maintain that attention is necessary for feature targets, and postulate that reaction time is unaffected by set size because attention can be directed to a feature target's location immediately by a process that is unaffected by the distractor items (Duncan, 1985; J. C. Johnston \& Pashler, 1988; Julesz, 1984). Although these theories propose different process- 
ing mechanisms, they make similar predictions about reaction time and accuracy, thereby leaving these basic issues unresolved.

In the present study, we attempted to distinguish between these competing explanations of visual search performance by recording event-related potentials (ERPs) simultaneously with reaction time (RT) measures. ERPs are scalp-recorded electrical potentials generated by neural activity associated with specific sensory, cognitive, and motor processes (see Donchin, Karis, Bashore, Coles, \& Gratton, 1986; Hillyard \& Kutas, 1983). Unlike behavioral measures, ERPs provide a continuous index of processing between the stimulus and response, and they can differentiate activity produced in separate brain regions. As a result, ERP data can be used to isolate different processing stages and processing structures (e.g., Coles, Gratton, Bashore, Eriksen, \& Donchin, 1985; Hillyard \& Münte, 1984; Osman, Bashore, Coles, Donchin, \& Meyer, 1988; Wijers et al., 1987).

The latency of the P3 (or P300) component has been shown to index the duration of stimulus recognition and classification processes, independently of subsequent stages such as response selection and execution (DuncanJohnson, 1981; Kutas \& Donchin, 1978; Kutas, McCarthy, \& Donchin, 1977). For example, P3 latency and RT both increase when noise elements are introduced around a tobe-identified stimulus, but only RT increases when the stimulus and response are made incompatible (Magliero, Bashore, Coles, \& Donchin, 1984; McCarthy \& Donchin, 1981). P3 latency can therefore be used to determine which processing stages are affected by set size during visual search: If the effects of set size on RT for conjunction targets are due to an increase in the duration of stimulus evaluation, then the slopes relating P3 latency and RT to set size should be identical. A similar logic has been used to interpret ERPs recorded during memory search tasks (see, e.g., Adam \& Collins, 1978; Ford, Roth, Mohs, Hopkins, \& Kopell, 1979; Gomer, Spicuzza, \& O'Donnell, 1976; Michalewski, Patterson, Pratt, Barret, \& Starr, 1988). In these experiments, P3 latency increased linearly as a function of memory set size, but the slope was shallower for P3 latency than for RT, suggesting that part of the effect of memory set size on RT was due to postrecognition processes.

While P3 latency can be used to determine whether the effects of set size are confined to stimulus evaluation processes, in the present study we also used P3 amplitude data to test the proposition that the detection of conjunction targets requires a serial search process rather than a limited capacity, parallel process. The amplitude of the P3 is highly sensitive to target probability, both global (over an entire block) and local (over the immediately preceding stimuli). Specifically, P3 amplitude increases as global target probability decreases and is larger for events that differ from the immediately preceding events (Duncan-Johnson \& Donchin, 1977; Squires, Petuchowski, Wickens, \& Donchin, 1977; Squires, Wickens, Squires, \& Donchin, 1976).
By definition, a serial search represents a sequence of decisions regarding stimulus identity, one for each item in the array. Since a positive (target-present) decision occurs for at most one item per stimulus array while all other items require a negative decision, the negative decisions are much more probable than the search-terminating positive decision. In addition, the final negative decision on a negative trial is preceded by several negative decisions, resulting in a high local probability. This combination of high global and local probabilities should result in a very small P3 amplitude for the final decision on negative trials in a serial search. In contrast, the final decision on a positive trial should elicit a large P3, because it is an improbable positive decision preceded by several negative decisions. Moreover, if the search is serial, P3 amplitude for positive trials should increase as a function of set size, because the number of negative decisions preceding the search-terminating positive decision increases as the set size increases.

The hypothesis of a limited capacity, parallel process makes very different predictions about P3 amplitude during the search for conjunction targets. With a parallel search process, one would not expect $\mathrm{P} 3$ amplitude to increase as a function of set size on positive trials, since the number of negative decisions preceding a positive decision would not be affected by set size unless the search were serial. Indeed, a reduction in P3 amplitude would be predicted for larger set sizes, on the grounds that target detections would be made with decreased levels of confidence due to capacity limitations; previous research has shown that P3 amplitude decreases sharply for less confident perceptual decisions (Johnson, 1984, 1986; Johnson \& Donchin, 1978; Paul \& Sutton, 1972; Squires, Squires, \& Hillyard, 1975).

The serial search model makes additional predictions concerning the effects of stimulus sequence on P3 amplitude. All negative trials and most positive trials begin with several negative decisions, which should elicit very little P3 activity due to their high global and local probabilities. However, if the preceding stimulus array contained a target, then the final decision on the preceding trial will have been positive, thereby decreasing the local probability of the first few negative decisions on the current trial. This decreased local probability should in turn produce greater $\mathrm{P} 3$ amplitude for the initial negative decisions. Since positive trials also typically begin with a few negative decisions, this sequential effect should be present for both positive and negative trials.

We are explicitly assuming here that each decision within the perceptual analysis of a single stimulus array will produce a $\mathrm{P} 3$ wave, the amplitude of which will vary according to the global and local probabilities of the decision. While it may seem unusual to posit the occurrence of more than one $\mathrm{P} 3$ wave for a single trial, several other studies have provided evidence that single stimuli can elicit multiple P3 waves (e.g., Johnson and Donchin, 1985; V. S. Johnston, Miller, \& Burleson, 1986; Stuss \& Picton, 1978) and that many P3 waves can occur within 
a short period of time (Woods, Courchesne, Hillyard, \& Galambos, 1980).

If the search is parallel rather than serial, the most obvious prediction is that the local probability of a decision will be smaller, and the associated P3 amplitude larger, when the preceding trial is the opposite of the current trial. For negative trials, therefore, both the serial and parallel models predict greater P3 amplitude when the preceding trial is positive. For positive trials, however, the serial model predicts greater $\mathrm{P} 3$ amplitude (during the first few hundred milliseconds after stimulus onset) when the preceding trial is also positive, whereas the parallel model predicts greater $\mathbf{P} 3$ amplitude when the preceding trial is negative.

As discussed above, feature integration theory posits the existence of different target detection processes for feature targets versus conjunction targets, whereas alternative hypotheses propose a single, attention-demanding detection process for both target types. ERP recordings may help adjudicate this dispute by testing whether qualitatively different ERP components accompany the detection of feature and conjunction targets, thus indicating the presence of different processes.

In the present experiment, we used a method described by Treisman and Souther (1985) to induce parallel and serial processing. These authors reasoned that an item containing a feature that is absent from the distractors could be detected in parallel, whereas an item that was distinguished from the distractors only by the absence of a feature could not. Therefore, if two items are identical except that one contains a feature that is absent in the other, then a serial search will be required when the featureabsent item is the target among feature-present distractors, but a parallel search will be possible when the featurepresent item is the target among feature-absent distractors. In one experiment, for example, a circle was the target and a circle with an intersecting line was the distractor. The detection of the plain circle target appeared to require a serial self-terminating search; when the circle with the line was the target and the plain circle was the distractor, however, the search appeared to be parallel, presumably because the line could be detected preattentively.

A similar paradigm was used in the present experiment. ${ }^{1}$ ERPs were recorded simultaneously with behavioral measures to test the proposition that the search for feature absence requires the serial repetition of a perceptual process, whereas the search for feature presence can be accomplished by a qualitatively different parallel system. The results indicated that a serial self-terminating search is indeed utilized for feature-absent targets and that different processes are engaged during the detection of featurepresent targets.

\section{METHOD}

\section{Subjects}

Twelve college students ( 7 male) were paid to participate in this experiment. The subjects were between 18 and 24 years old, were right-handed, and had normal or corrected-to-normal vision. Four initial subjects had excessive alpha activity or ocular artifacts and were replaced.

\section{Stimuli}

The stimuli in this experiment consisted of arrays of 4,8 , or 12 items placed at random locations on a black and white computer monitor. The screen was $100 \mathrm{~cm}$ from the subject and the items were located within an imaginary rectangle $9.8^{\circ}$ wide and $7.5^{\circ}$ high, centered on a white fixation point. There were two types of items: a triangle with one vertical side (the left side) and two oblique sides (pointing toward the right), and the same triangle with an additional feature, a horizontal line extending leftward from the vertical side (see Figure 1). There were two conditions: a feature-absent condition, in which the plain triangle was the target and the trianglewith-line was the distractor, and a feature-present condition, in which the triangle-with-line was the target and the plain triangle was the distractor. On negative trials ( $p=.5$ ), all items were distractors. On positive trials $(p=.5$ ), one of the items was the target and the others were distractors. The positions of the target and distractor items were randomized from trial to trial. Stimulus arrays composed of the three different set sizes were presented in unpredictable order with equal probability. Each stimulus was presented for a duration of $1.5 \mathrm{sec}$, and the interval between successive stimulus onsets varied randomly between 3.0 and $3.5 \mathrm{sec}$.

\section{Procedure}

The feature-present and feature-absent search conditions were run in separate blocks of trials, each consisting of 60 stimulus arrays presented in random order. There were 10 blocks of stimuli in each condition, and the order of blocks was randomized across subjects. Subjects were instructed to respond with one hand if the target was present and with the other hand if the target was absent, taking exactly as much time as was necessary to make an accurate response. Half of the subjects used the right hand to signal target presence and half used the left. The subjects were instructed to suppress blinks and eye movements as much as possible. Before the recording began, the subjects performed two practice blocks in each condition.

\section{Recording}

The EEG was recorded from standard left and right hemisphere scalp sites overlying frontal, central, parietal, occipital, and temporal cortex (International 10/20 System names: F3, F4, C3, C4,

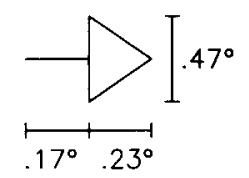

Feature-Absent Feature-Present

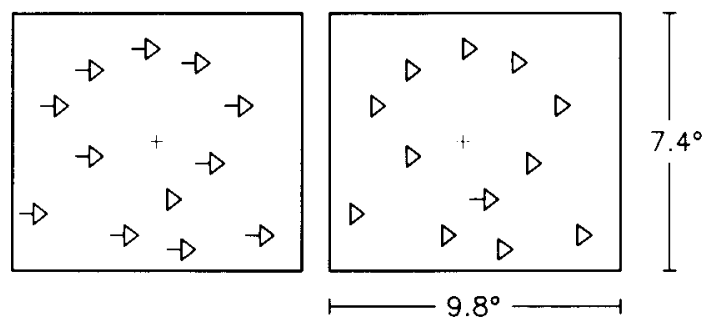

Figure 1. Examples of positive (target-present) stimuli in the feature-absent (left) and feature-present (right) conditions. The set size for these examples is 12 items. The fixation point is represented here by a plus symbol. The dimensions of an individual featurepresent item are given at the top. 
P3, P4, O1, O2, T5, T6). The ERPs were algebraically rereferenced to the average of the left and right mastoids after averaging. The horizontal EOG was recorded between the left and right external canthi to monitor lateral eye position, and the vertical EOG was recorded from beneath the left eye, referenced to the left mastoid, to monitor blink activity. The recordings were made through $\mathrm{Ag} / \mathrm{AgCl}$ electrodes attached to the skin with collodion or adhesive collars. The potentials were amplified with an 8-sec time constant and a $60-\mathrm{Hz}$ low-pass filter (frontal and central sites) or a 9.2-sec time constant and a 100-Hz low-pass filter (all other sites). The voltages were digitized at $256 \mathrm{~Hz}$ by a minicomputer and stored with stimulus and response codes on digital tape for off-line analysis.

\section{Data Analysis}

The EEG was averaged off-line, using an automatic artifact detection system that rejected trials with blinks or large eye movements. Most subjects reported being unable to perform the task in the feature-absent condition without some eye movement, so a strict rejection criterion could not be employed. However, a separate analysis assessed the number of eye movements by counting the number of trials on which the peak-to-peak voltage in the horizontal eye movement channel exceeded $30 \mu \mathrm{V}$ (note that this is a strict criterion that occasionally included artifacts from other sources, such as blinks). Trials with incorrect behavioral responses were also excluded from the averages.

Since the time elapsing between stimulus onset and the subject's final decision is highly variable in a serial self-terminating search, the ERP components related to search-terminating decisions in the feature-absent condition were expected to be poorly time-locked to stimulus onset. However, much less variance was expected in the time-locking between these ERP waves and the behavioral response. Therefore, two types of averages were calculated, one in which stimulus onset was the time-locking event (producing stimulus-locked averages) and one in which the behavioral response was the time-locking event (producing response-locked averages). Adaptive filtering (Glaser \& Ruchkin, 1976; Woody, 1967) was attempted, but it produced poor results because of the extremely long search window required $(300-2,500 \mathrm{msec})$ and the small P3 waves elicited by some stimulus types.

The amplitude and latency of the $\mathrm{P} 1, \mathrm{~N} 1$, and $\mathrm{P} 2$ peaks were measured at the amplitude peak in the intervals from 50 to $150 \mathrm{msec}$ (P1), 125 to $225 \mathrm{msec}(\mathrm{N} 1)$, and 150 to $250 \mathrm{msec}(\mathrm{P} 2)$. The P1 and $\mathrm{N} 1$ were measured at occipital, temporal, and parietal sites, and the $\mathrm{P} 2$ was measured at frontal and central sites. These measures were derived from the stimulus-locked averages. Amplitude was measured as the difference between peak amplitude and the mean voltage during a 100 -msec prestimulus baseline; latency was measured relative to stimulus onset. An additional set of stimuluslocked averages was constructed to test for the existence of an N2 wave that has been observed in previous studies at posterior scalp sites contralateral to the position of the target (Heinze, Luck, Mangun, \& Hillyard, 1990; Luck, Heinze, Mangun, \& Hillyard, 1990; Luck \& Hillyard, 1988). The data for positive trials were averaged separately on the basis of stimulus position (left or right), and the $\mathrm{N} 2$ was quantified as the mean amplitude between 250 and $350 \mathrm{msec}$ at parietal, occipital, and temporal sites.

The amplitude and latency of the P3 wave were measured at all scalp sites in both the stimulus-locked and the response-locked averages. In the stimulus-locked averages, latency was measured as the time between stimulus onset and the maximum positive peak occurring between 400 and 1,600 msec poststimulus, and amplitude was measured as the mean voltage in this range. This broad measurement window was required because the P3 wave typically peaked just before the response, and responses were made throughout the duration of this window. Mean rather than peak amplitude was used for the P3, because the greater latency variation expected for larger set sizes can distort peak amplitude measures. Since the $P 3$ waves were often very broad, lacking a clear peak, P3 latency was also measured as the time required for the component to reach $50 \%$ of its mean amplitude over the measurement window (cf. Hansen \& Hillyard, 1988). For this measure, the mean voltage of each ERP waveform was measured between 300 and $1,600 \mathrm{msec}$, and the time point that divided this voltage $\times$ time "area" into equal halves was used as the P3 latency estimate. This " $50 \%$ area" measure was more stable than the peak latency measure, but the overall effects of the experimental manipulations were nearly identical for the two measures.

In the response-locked averages, P3 latency was measured as the time between the motor response and the maximum positive peak occurring in the window between $300 \mathrm{msec}$ preresponse and 100 msec postresponse; $\mathrm{P} 3$ amplitude was measured as the mean voltage within this latency range. There was no unambiguous amplitude baseline in the response-locked averages, so the mean amplitude of the entire period between 900 -msec preresponse and 900 -msec postresponse was employed (other baselining methods produced similar results).

Stimulus- and response-locked averages were also computed in a sequential analysis, in which trials were sorted on the basis of whether the preceding stimulus array was positive or negative. In order to retain an adequate signal-to-noise ratio, the trials were collapsed across set sizes for this analysis. Because the serial search model predicts that the occurrence of a positive decision on the preceding trial should affect the first few negative decisions within the current trial, the stimulus-locked $\mathrm{P} 3 \mathrm{~s}$ from this analysis were measured as the mean amplitude during the initial interval of P3 activity, from 300 to $600 \mathrm{msec}$ poststimulus. In addition, this analysis excluded Set Size 4, for which positive decisions in the early P3 latency range were highly probable on positive trials (a similar analysis that included Set Size 4 produced slightly smaller effects, but the levels of statistical significance were approximately equivalent due to the larger number of trials). The response-locked P3s for this sequential analysis included all set sizes, and were measured in the same manner as described for response-locked averages above.

All electrophysiological and behavioral measures were analyzed with repeated measures analyses of variance (ANOVAs), adjusting for nonsphericity with the Greenhouse-Geisser epsilon coefficient (Jennings \&Wood, 1976). For the initial data anaiyses, each ERP measure was analyzed with five factors: search task (feature-present vs. feature-absent); trial type (positive vs. negative); set size (4, 8 , or 12); electrode site (frontal, central, parietal, occipital, or temporal, depending on which sites were measured for a particular peak); and hemisphere (left electrodes vs. right electrodes). Whenever significant interactions involving the search task factor occurred, the feature-present and feature-absent conditions were analyzed separately to determine the nature of the interaction (pooled error estimates were not used in these analyses, thereby avoiding the inflated Type I and Type II error rates that may occur if the variance/covariance matrix is nonspherical). For the sequential analysis, the set size factor was replaced with a factor representing whether the preceding trial was positive or negative; for the analysis of the $\mathrm{N} 2$ wave as a function of stimulus location, the target presence factor was replaced with a target position factor.

\section{RESULTS}

\section{Behavioral Measures}

The mean reaction times are plotted in Figure 2. In the feature-absent condition, the functions relating set size to RT were highly linear, with linearity accounting for over 97\% of the variance in regression analyses of the mean RTs. The slope for negative trials (51.8 msec per item) 


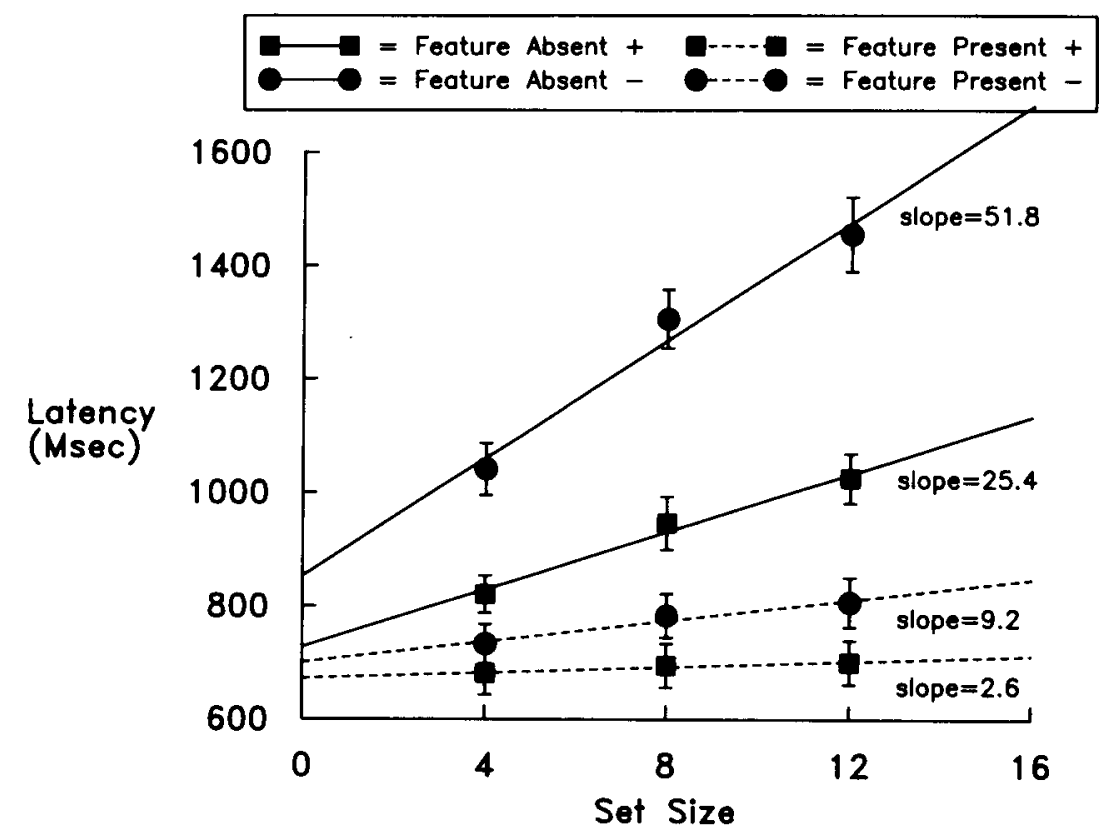

Figure 2. Mean reaction times ( $t S E M$ ) as a function of set size. Positive trials are indicated by a plus sign in the symbol key and negative trials are indicated by a minus. Regression lines are plotted for each condition, and their slopes are listed at the right.

was almost exactly twice as large as the slope for positive trials (25.4 msec per item), consistent with a serial, self-terminating search. In the feature-present condition, the slopes of the functions relating RT to set size were shallow and did not follow a 2:1 ratio for positive versus negative trials ( 2.6 and $9.2 \mathrm{msec}$ per item, respectively). These shallow slopes are consistent with a parallel search strategy.

An ANOVA was conducted on the RTs with three factors: search task (feature-present vs. feature-absent), trial type (positive vs. negative), and set size $(4,8$, or 12 items). All main effects and interactions were highly significant $(p<.001)$. When the feature-present and featureabsent conditions were analyzed separately, the trial type, set size, and trial type $\times$ set size interactions were still highly significant for both conditions $(p<.005)$. Thus, set size and trial type affected RT for both the featurepresent and feature-absent conditions, but the effects were much larger for the latter.

Target detection accuracy, shown in Table 1, was also differentially affected by set size in the feature-present and feature-absent conditions. Sensitivity (percent hits and $d^{\prime}$ ) decreased and criterion $(\beta)$ increased as set size increased in the feature-absent condition, but not in the feature-present condition. This resulted in a highly significant set size $\times$ search task interaction for each of the three detection parameters $(p<.005$ or lower). In separate comparisons, set size significantly affected all of the detection measures in the feature-absent condition $(p<.005$ or lower) and none in the feature-present condition $(p>.50$ or higher).

\section{P3 Latency}

Stimulus-locked ERP averages from the parietal sites are shown for the feature-present condition in Figure 3. In this condition, P3 peak latency did not vary as a function of set size for either positive or negative trials. However, the $50 \%$ area latency measure increased slightly as a function of set size for negative trials, probably due to the continued presence of ERP activity late in the recording epoch for the larger set sizes. On both positive and negative trials, P3 amplitude reached slightly higher peak values for the smallest set size.

The ERPs in the feature-absent condition, shown in Figure 4, differed markedly from those in the featurepresent condition. For positive trials in the feature-absent condition, the $\mathrm{P} 3$ peaked later and became broader as set size increased, consistent with the increasing RTs for these stimuli. For negative trials, however, the P3 was considerably smaller, and its latency was not strongly affected by set size. This contrasts with a large effect of set size on RT for these stimuli (cf. Figure 2).

Table 1

Target-Detection Accuracy Measures for Each Set Size in Each Search Condition

\begin{tabular}{ccccc}
\hline Search Type & Set Size & $\%$ Hits & $d^{\prime}$ & $\beta$ \\
\hline Feature-present & 4 & 98.0 & 4.48 & 2.04 \\
& 8 & 98.4 & 4.47 & 1.45 \\
& 12 & 98.6 & 4.50 & 1.52 \\
Feature-absent & 4 & 97.7 & 4.13 & 1.67 \\
& 8 & 89.6 & 3.43 & 5.20 \\
& 12 & 79.6 & 2.89 & 7.04 \\
\hline
\end{tabular}




\section{Feature-Present Condition}

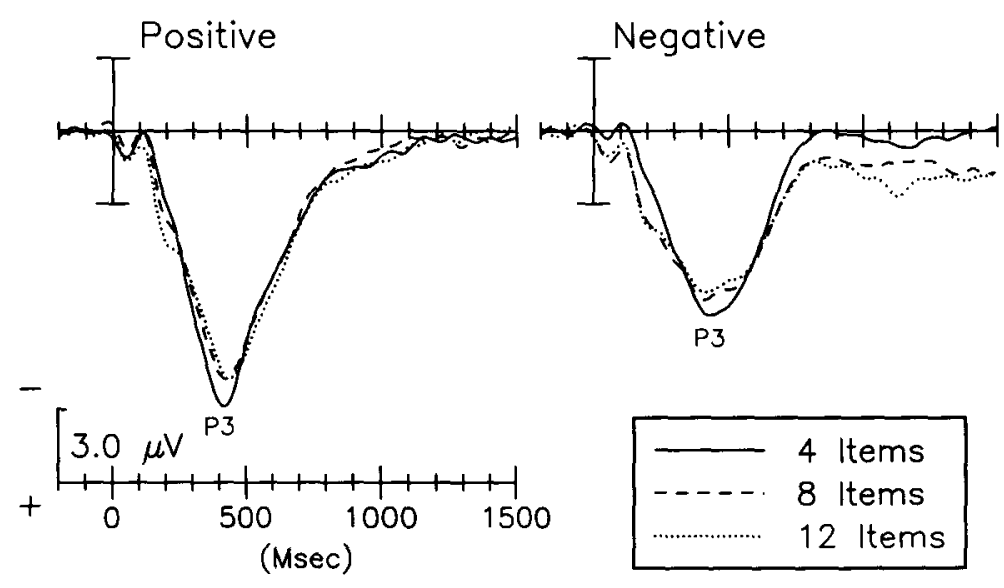

Figure 3. Grand average stimulus-locked ERPs in the feature-present condition, averaged over the P3 and P4 electrode sites. Each plot contains a separate ERP waveform for each set size. The left plot contains ERPs for positive trials and the right plot contains ERPs for negative trials.

The observation that set size strongly affected P3 latency only for the positive trials in the feature-absent condition was corroborated by a significant search task $\times$ trial type $\times$ set size interaction for both latency measures [50\% area: $F(2,22)=16.05, p<.001$; peak: $F(2,22)=5.53$, $p<.02]$. An analysis of the feature-absent condition alone yielded a significant interaction between trial type and set size $[50 \%$ area: $F(2,22)=6.25, p<.01$; peak: $F(2,22)=3.49, p<.05]$, but there were no significant effects involving set size for the feature-present condition when it was analyzed separately.

The effects of set size on RT and P3 latency (50\% area measure from the stimulus-locked averages) are compared for the feature-present condition in Figure 5 and for the feature-absent condition in Figure 6. In the feature-present condition, neither P3 latency nor RT was strongly affected by set size for positive trials, but both RT and P3 latency increased slightly as a function of set size on negative trials. In the feature-absent condition, the slopes of the functions relating set size to RT and P3 latency were almost identical for positive trials. On negative trials, however, there was no reliable effect of set size on P3 latency, whereas RT increased sharply as set size increased. ${ }^{2}$.

\section{P3 Amplitude}

The effects of set size on P3 latency and RT were essentially identical in every case except for the negative trials in the feature-absent condition, suggesting that substantial P3 activity was time-locked to the response for the other trial types. The response-locked averages, shown

\section{Feature-Absent Condition}

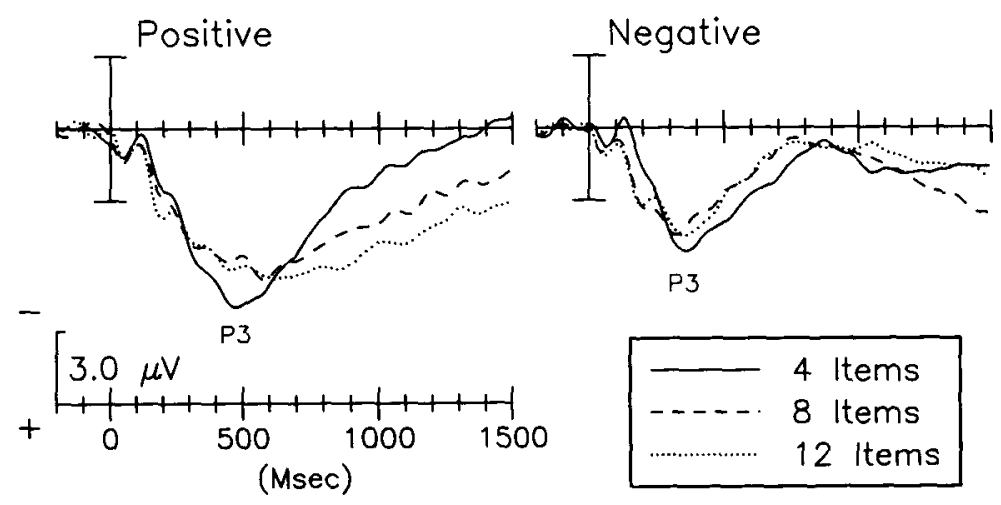

Figure 4. Grand average stimulus-locked ERPs in the feature-absent condition, averaged over the P3 and P4 electrode sites. Each plot contains a separate ERP waveform for each set size. The left plot contains ERPs for positive trials and the right plot contains ERPs for negative trials. 
in Figure 7, support this interpretation: well-defined response-locked activity occurred in every case except for the negative, feature-absent trials. This wave also had the same scalp distribution as the stimulus-locked P3 wave and will therefore be considered the same component. As in the stimulus-locked averages, the response-locked P3 in the feature-present condition was larger for positive trials than for negative trials at posterior scalp sites and was somewhat larger for the smallest set size. In contrast, response-locked $\mathrm{P} 3$ amplitude in the feature-absent condition increased with increasing set size for positive trials, and there was essentially no P3 activity for negative trials. Instead, there was a gradual transition from negative to positive that was largest at frontal sites, perhaps due to the offset of a prior slow potential such as the contingent negative variation (Desmedt \& Debecker, 1979) or search negativity (Wijers, Mulder, Okita, Mulder, \& Scheffers, 1989).

Mean amplitude in the P3 latency range is presented for the stimulus- and response-locked averages in Table 2. In both types of averages, P3 amplitude increased with set size for positive feature-absent trials; this effect was not seen in the feature-present condition. The different effects of set size in the feature-absent and feature-present conditions resulted in a significant search task $\times$ trial type $X$ set size interaction for the stimulus-locked averages $[F(2,22)=11.35, p<.001]$ and for the response-locked averages $[F(2,22)=10.95, p<.02]$. For both types of

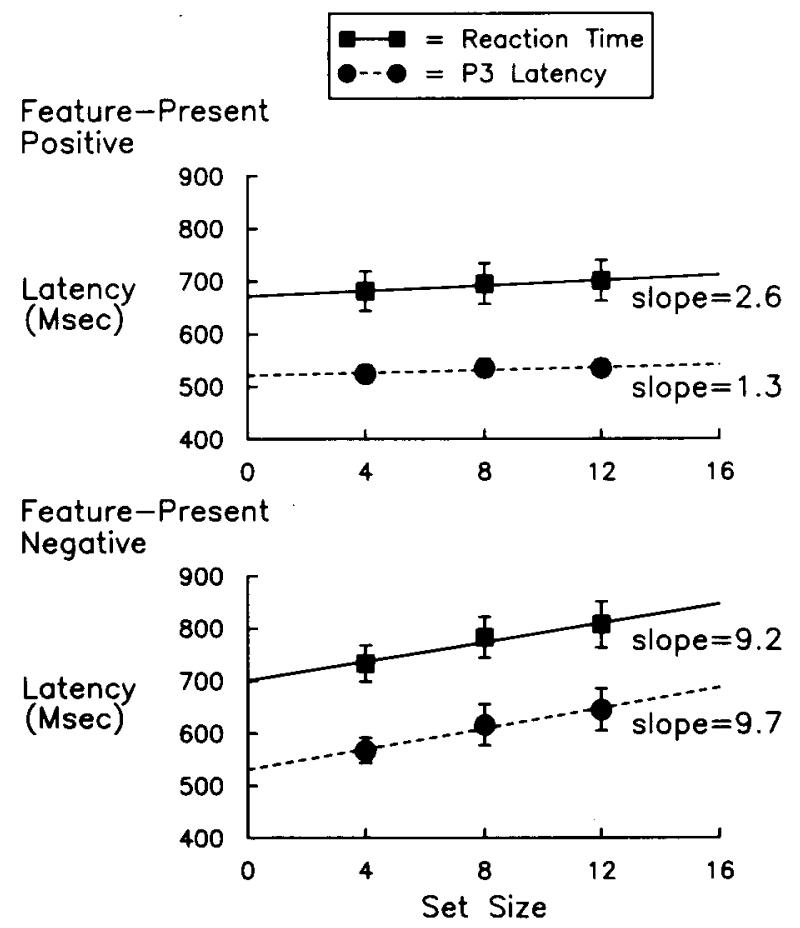

Figure 5. Mean reaction time and $P 350 \%$ area latency ( \pm SEM) as a function of set size for positive (top) and negative (bottom) trials in the feature-present condition. The $\mathrm{P} 3$ latency measure was averaged over P3 and P4 electrode sites.

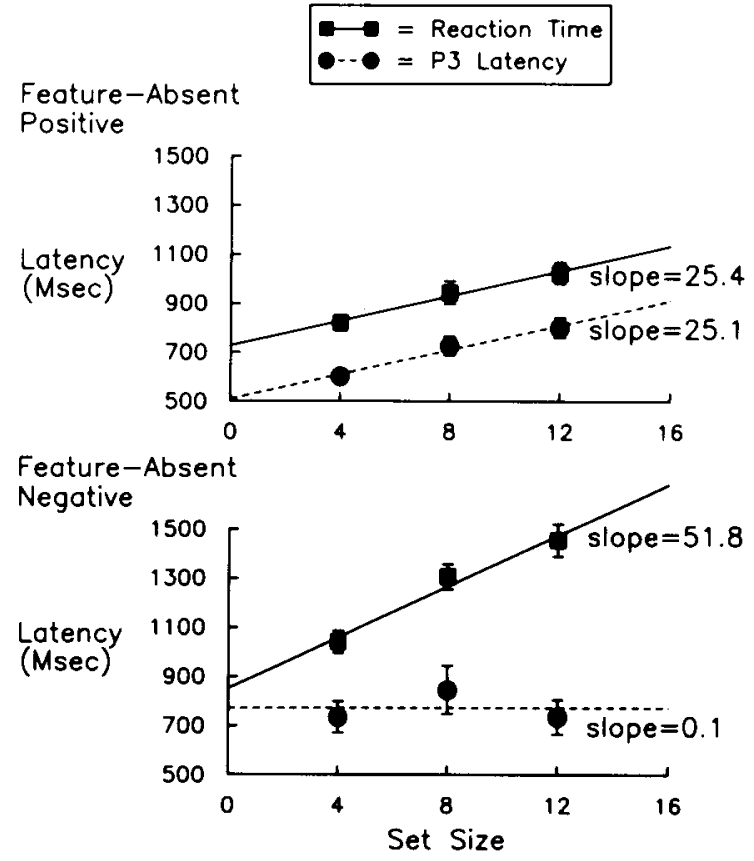

Figure 6. Mean reaction time and $P 350 \%$ area latency $( \pm S E M)$ as a function of set size for positive (top) and negative (bottom) trials in the feature-absent condition. The P3 latency measures were averaged over P3 and P4 electrode sites from the stimulus-locked averages. Note that the vertical scale is expanded relative to Figure 5 .

averages, the trial type $\times$ set size interaction was highly significant in analyses of the feature-absent condition alone ( $p<.005$ or lower). In analyses of the feature-present condition, this interaction was not significant in the stimulus-locked averages, but it reached significance in the response-locked averages $[F(2,22)=4.46, p<.05]$. Note that in the feature-present condition, this interaction was due to increased P3 amplitudes for smaller set sizes on negative trials, whereas the same interaction in the feature-absent condition was a result of increased P3 amplitudes for larger set sizes on positive trials.

\section{Sequential Analysis}

The stimulus-locked averages from the sequential analysis are displayed in Figure 8. For the feature-present condition, P3 amplitude was slightly larger when the preceding stimulus was opposite to the current stimulus. In other words, for positive trials the P3 was larger when the preceding trial was negative, and for negative trials the P3 was larger when the preceding trial was positive. In the feature-absent condition, however, P3 amplitude was larger when the preceding trial was positive, regardless of whether the current trial was positive or negative.

The differential sequential effects for the feature-present versus feature-absent conditions were largest at the parietal sites, resulting in a significant search task $\times$ preceding trial type $\times$ electrode site interaction $[F(4,44)=4.91$, $p<.005]$. When the feature-absent condition was analyzed separately, the sequential effect was highly signifi- 


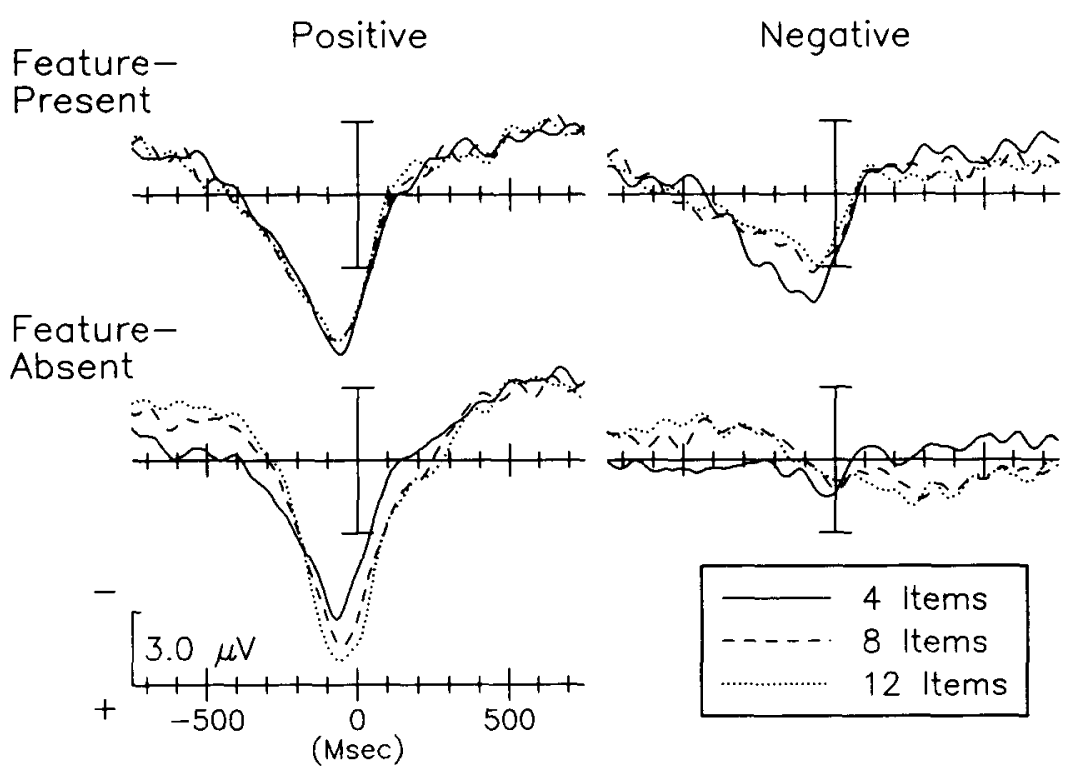

Figure 7. Grand average response-locked ERPs, averaged over P3 and P4 electrode sites, for the feature-present (top row) and feature-absent (bottom row) conditions. Each plot contains a separate ERP waveform for each set size. The left column contains ERPs for positive trials and the right column contains ERPs for negative trials. Time zero represents response occurrence. The average voltage across the entire epoch was used as the amplitude baseline.

cant [interacting with electrode site: $F(4,44)=14.37$, $p<.001]$, but it was not significantly different for positive versus negative trials. A separate analysis of the feature-present condition indicated that the small sequential effects did not reach significance in that condition.

According to the serial search model, the effects of stimulus sequence on the $\mathrm{P} 3$ for positive trials were due to an effect of local probability on negative decisions occurring at the beginning of most trials. These negative decisions can be differentiated from the search-terminating positive decision by examining the effects of sequential order on the response-locked averages, which should

Table 2

P3 Amplitude (in Microvolts) Measured as the Average Amplitude between $\mathbf{4 0 0}$ and $1,600 \mathrm{msec}$ Poststimulus for the Stimulus-Locked Averages and between 300 msec Preresponse and 100 msec Postresponse for the Response-Locked Averages, Averaged over Parietal Electrode Sites

\begin{tabular}{|c|c|c|c|c|}
\hline Search Type & $\begin{array}{l}\text { Trial } \\
\text { Type }\end{array}$ & $\begin{array}{l}\text { Set } \\
\text { Size }\end{array}$ & $\begin{array}{c}\text { Stimulus- } \\
\text { Locked P3 }\end{array}$ & $\begin{array}{l}\text { Response- } \\
\text { Locked P3 }\end{array}$ \\
\hline Feature-present & Positive & $\begin{array}{r}4 \\
8 \\
12\end{array}$ & $\begin{array}{l}2.86 \\
2.74 \\
2.91\end{array}$ & $\begin{array}{l}4.37 \\
4.19 \\
4.28\end{array}$ \\
\hline Feature-present & Negative & $\begin{array}{r}4 \\
8 \\
12\end{array}$ & $\begin{array}{l}2.72 \\
2.01 \\
2.02\end{array}$ & $\begin{array}{l}3.19 \\
2.33 \\
1.96\end{array}$ \\
\hline Feature-absent & Positive & $\begin{array}{r}4 \\
8 \\
12\end{array}$ & $\begin{array}{l}2.94 \\
3.77 \\
4.59\end{array}$ & $\begin{array}{l}4.12 \\
4.75 \\
5.25\end{array}$ \\
\hline Feature-absent & Negative & $\begin{array}{r}4 \\
8 \\
12\end{array}$ & $\begin{array}{l}1.99 \\
2.01 \\
1.86\end{array}$ & $\begin{array}{l}0.79 \\
0.02 \\
0.17\end{array}$ \\
\hline
\end{tabular}

primarily contain $\mathrm{P} 3$ activity related to the terminal decision. As can be seen in Figure 9, the effect of sequential order on the P3 for positive, feature-absent trials was reversed in the response-locked averages relative to the stimulus-locked averages. Whereas the stimulus-locked P3 was larger when the preceding trial was positive, the response-locked P3 was larger when the preceding trial was negative, indicating that the sequential effects evident in the stimulus-locked averages were not due to changes in the search-terminating positive decision.

In both the feature-present and the feature-absent conditions, the response-locked $\mathrm{P} 3 \mathrm{~s}$ were larger when the preceding trial was opposite to the current trial, and this effect was largest at parietal sites, resulting in a significant trial type $\times$ preceding trial type $\times$ electrode site interaction $[F(4,44)=3.98, p<.01]$. The sequential effects were essentially identical in the feature-present and feature-absent conditions, and none of the interactions involving search task and preceding trial type approached significance.

\section{P3 Scalp Distribution}

Figure 10 shows the scalp distribution of the stimuluslocked ERPs for positive and negative trials, collapsed over set sizes. These scalp distributions are summarized in Figure 11, in which the difference between positivetrial and negative-trial P3 amplitudes is plotted as a function of scalp site. In the feature-absent condition, the difference between positive and negative trials was maximal at parietal sites and had a similar scalp distribution to the P3 for positive or negative trials considered separately. In the feature-present condition, however, this 


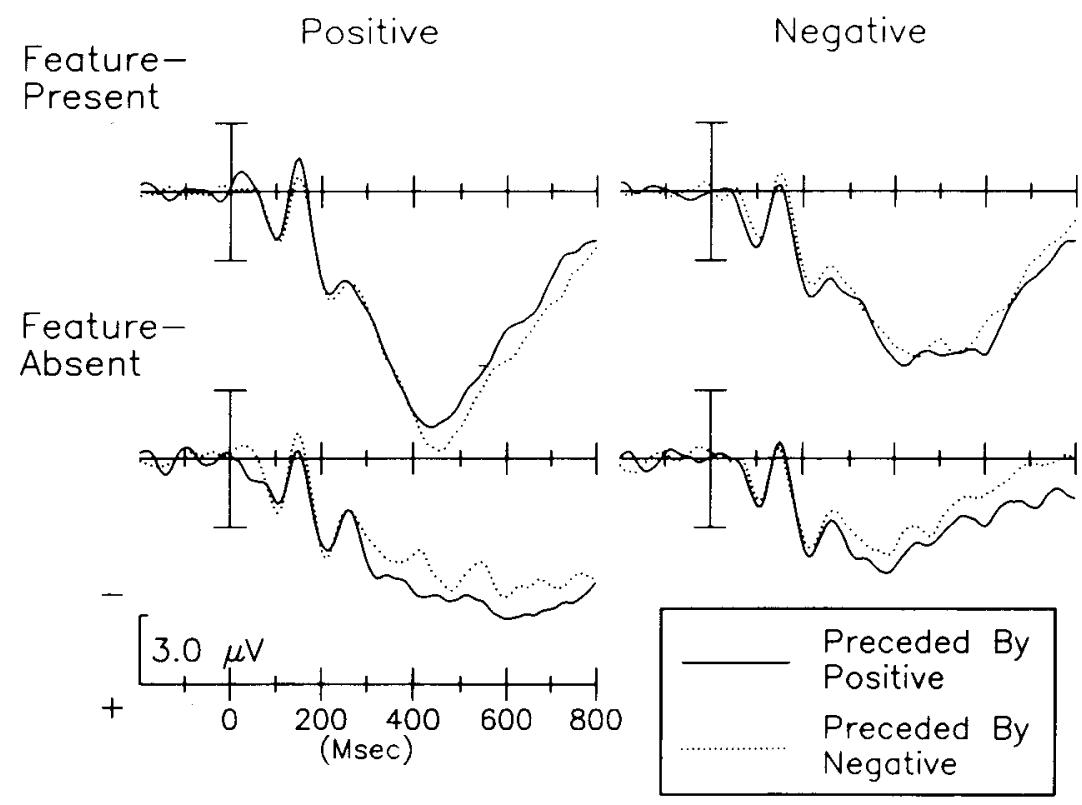

\begin{abstract}
Figure 8. Grand average stimulus-locked ERPs from the sequential analysis, averaged over P3 and P4 electrode sites. These ERPs were elicited by positive or negative trials, sorted on the basis of whether the preceding trial was positive (solid line) or negative (dotted line), and collapsed over Set Sizes 8 and 12. Time zero represents stimulus onset.
\end{abstract}

difference was maximal at the occipital sites and had a different scalp distribution from the overall P3 on positive or negative trials. This resulted in a significant interaction between search task, trial type, and electrode site $[F(1,11)=8.67, p<.02]$, and suggests the presence of different target-sensitive ERP components in the featurepresent and feature-absent conditions.

The presence of this occipitally maximal component in the feature-present condition does not imply that the typical parietal P3 component was absent. Despite the occipital maximum of the difference between positive and negative trials, the overall ERP activity in the P3 measurement window was largest at the parietal electrodes, and

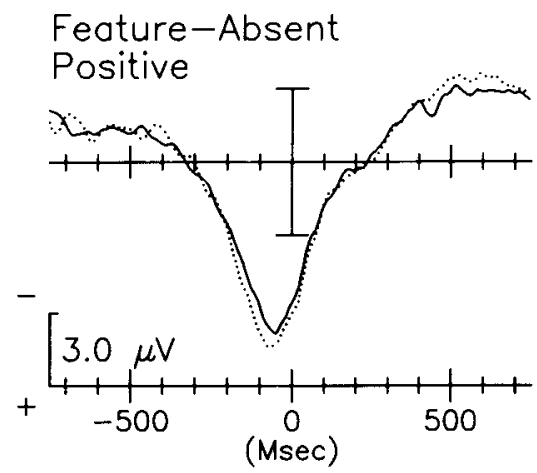

Figure 9. Grand average response-locked ERPs for positive trials in the feature-absent condition, averaged over P3 and P4 electrode sites. These ERPs were sorted on the basis of whether the preceding trial was positive (solid line) or negative (dotted line), and collapsed over all set sizes. Time zero represents response occurrence.
Figure 7 shows that this activity was well time-locked to the behavioral response. These results suggest that the occipitally maximal component overlapped a parietally maximal P3, rather than replacing it altogether.

\section{Other Peaks}

The $\mathrm{P} 1, \mathrm{~N} 1, \mathrm{P} 2$, and $\mathrm{N} 2$ peaks tended to increase in amplitude and decrease in latency as set size increased (see Figures 3 and 4), probably because of changes in physical stimulus parameters rather than decision processes. The set size main effect was significant for $\mathrm{P} 1 \mathrm{am}$ plitude $[F(2,22)=8.01, p<.02]$, N1 latency $[F(2,22)=$ 27.74, $p<.001]$, and $\mathrm{P} 2$ latency $[F(2,22)=12.27, p<$ $.001]$. The interaction of set size and scalp site was significant for $\mathrm{N} 1$ amplitude $[F(4,44)=5.85, p<.02]$ and for the 250-350-msec mean amplitude measure of the N2 $[F(8,88)=5.77, p<.005]$.

In both the feature-present and the feature-absent conditions, the $\mathrm{N} 2$ measure was more negative at posterior scalp sites contralateral to the position of the target, resulting in a significant target position $\times$ hemisphere interaction $[F(1,11)=23.74, p<.001]$ and an interaction of these factors with electrode site $[F(4,44)=5.28$, $p<.005]$. This $\mathrm{N} 2$ was much longer in duration and was more broadly distributed in the feature-absent condition, but the presence of eye movements toward the target in this condition may have confounded these results.

\section{Eye Movements}

The percentages of trials containing eye movements (or other artifacts in the horizontal EOG channel) for each condition are presented in Table 3. The percentage of eye 


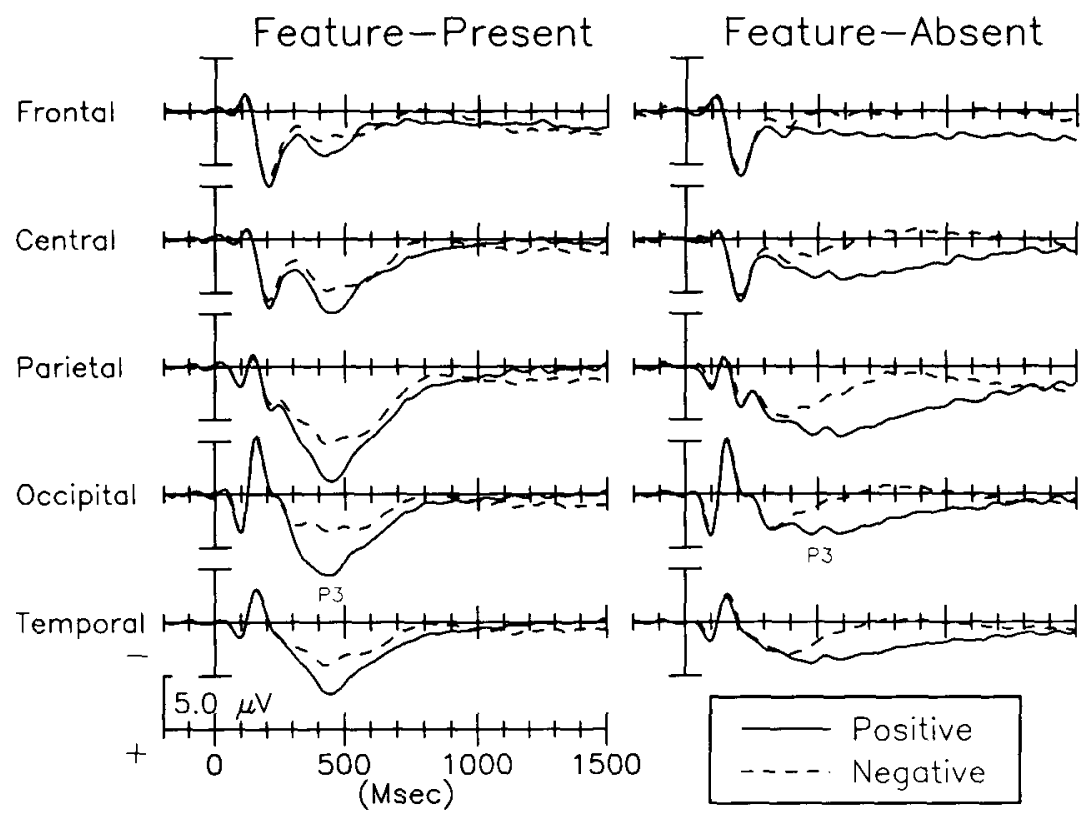

Figure 10. Scalp distribution of grand average stimulus-locked ERPs, collapsed over set sizes and left/right electrode pairs, for the feature-absent (left) and feature-present (right) conditions. The solid lines represent positive trials and the dashed lines represent negative trials.

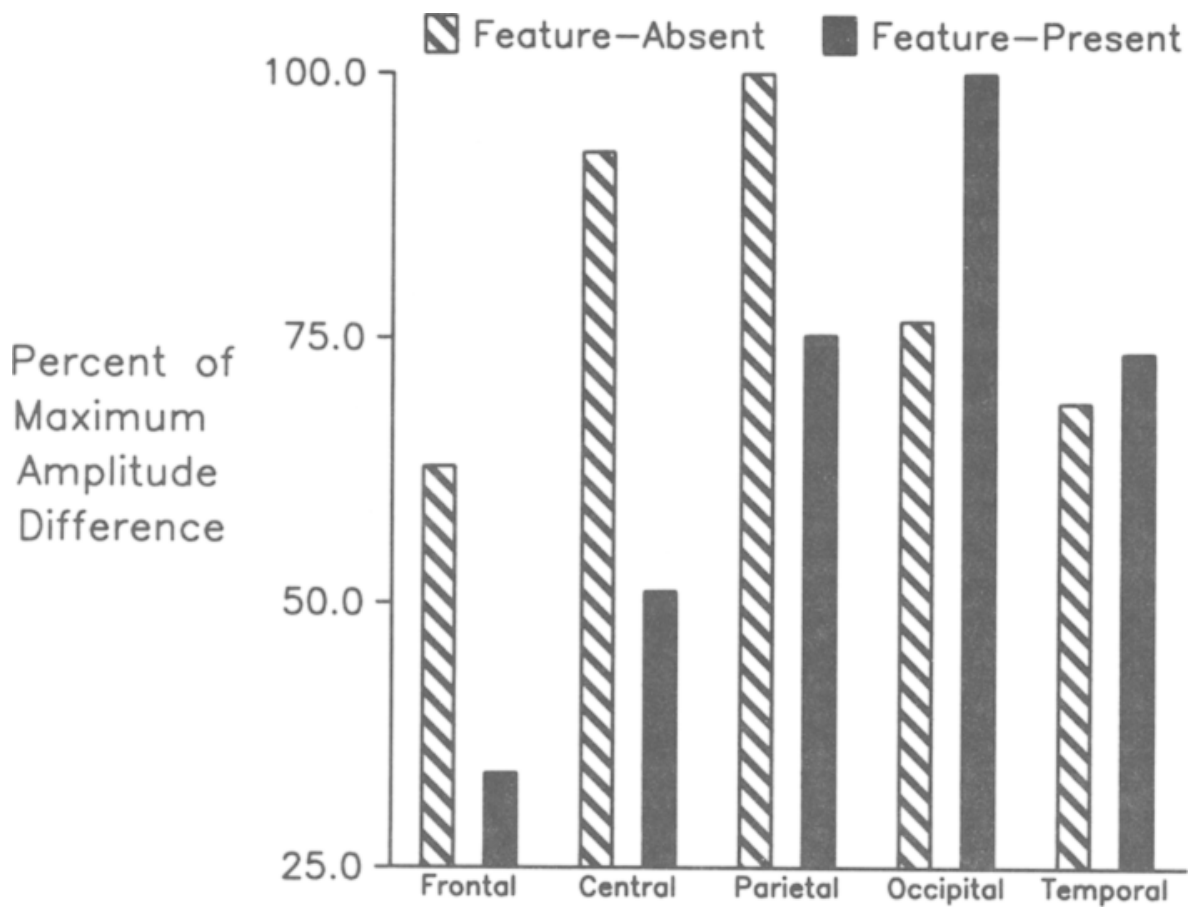

Figure 11. Difference between positive-trial and negative-trial $P 3$ amplitude as a function of scalp site for the feature-present and feature-absent conditions. The differences were derived from the stimuluslocked averages and were averaged over left/right electrode pairs. The scores are expressed as a percentage of the maximum amplitude difference for each condition. 
Table 3

Mean Percentage of Trials with Eye Movements or Other Horizontal EOG Activity Exceeding $30 \mu \mathrm{V}$ in Peak-to-Peak Amplitude

\begin{tabular}{clccc}
\hline Search Type & Trial Type & 4 Items & 8 Items & 12 Items \\
\hline Feature-absent & Positive & 15.8 & 21.2 & 25.8 \\
& Negative & 33.0 & 45.2 & 44.1 \\
Feature-present & Positive & 11.1 & 11.3 & 11.8 \\
& Negative & 14.0 & 16.0 & 18.4 \\
\hline
\end{tabular}

movements generally paralleled the mean RTs. There were more eye movements in the feature-absent condition than in the feature-present condition; there were more on negative than on positive trials; and the number of eye movements increased with set size in the feature-absent condition. In a search type $\times$ trials type $\times$ set size ANOVA, all main effects and interactions were significant $(p<.05)$ except for the three-way interaction.

\section{DISCUSSION}

\section{Is the Set Size Effect Perceptual or Postperceptual?}

One of the issues addressed in this experiment was whether the effects of set size on RT for feature-absent targets are due to changes in the duration of a perceptual process or, alternatively, some postperceptual process. For example, target detection accuracy decreased as set size increased, and this may have caused subjects to divert processing resources away from response selection and execution, thus slowing RT without affecting the duration of perceptual processing. The slopes relating set size to P3 latency and RT were essentially identical for positive trials in the feature-absent condition, however, indicating that the effects of set size on RT were due to processes occurring before the stimulus was categorized as a target. This inference is based on considerable evidence that P3 latency in decision tasks is an index of the duration of the perceptual processing leading to stimulus classification (see the introduction). The ERP results are therefore in accord with the proposal that set size affects the duration of perceptual processing. ${ }^{3}$

\section{Serial Versus Parallel Models}

The existence of a linear relationship between set size and the duration of perceptual processing does not necessarily entail that the items are being searched serially. As has been noted by Pashler and Badgio (1985, 1987), such results are also compatible with limited capacity, parallel processing models. The 2:1 slope ratio observed in the present experiment also constituted a strong prediction of the serial self-terminating search model, but smaller ratios have been found in many similar experiments (Pashler, 1987; Pashler \& Badgio, 1985; Treisman \& Gelade, 1980). In addition, a 2:1 slope ratio would be produced with a parallel processor if subjects were more confident in targetpresent decisions than in target-absent decisions and simply "double-checked" the stimuli on negative trials.
However, the serial and parallel models make very different predictions about $\mathrm{P} 3$ amplitude during the search for feature absence, as was noted in the introduction. Briefly, the serial search model predicts that the final decision on negative trials will have a very high probability and thus elicit very little $P 3$ activity, whereas the probability of the final decision on positive trials will be low and will decrease as set size increases, thereby increasing P3 amplitude. Different predictions are made by the parallel model, on the basis of the assumption that target detection confidence decreases as set size increases, resulting in decreased P3 amplitude. Since accuracy did indeed decrease as set size increased (Table 1), the assumption of decreased confidence seems likely to be true. Despite the reduction in accuracy, however, P3 amplitude actually increased with increasing set size on positive trials in the feature-absent condition, as predicted by the serial model. In addition, there was essentially no responselocked $\mathrm{P} 3$ activity on negative feature-absent trials, again consistent with the serial model. These results therefore support the serial search hypothesis proposed by feature integration theory and argue against a limited capacity parallel process.

A very different pattern of results was observed in the feature-present condition. Both positive and negative trials produced large P3 waves, and P3 amplitude decreased as set size increased. This set size effect, along with the small positive RT and P3 latency slopes observed in this condition, suggests that a parallel process with some capacity limitations may have been responsible for the detection of feature targets.

Additional predictions of the serial search model were tested by considering the effects of stimulus order on the local probabilities of positive and negative decisions. In a serial search, both positive and negative trials will usually begin with one or more negative decisions, and these decisions should produce larger P3 waves when the previous trial is positive rather than negative. In a parallel search, however, there are no negative decisions interposed between successive search-terminating decisions, and the $\mathrm{P} 3$ elicited by a positive trial should therefore be smaller, not larger, when the preceding trial is negative. The predictions of the serial model were corroborated in the feature-absent condition, in which P3 amplitude was larger for both positive and negative trials when preceded by a positive trial, whereas the predictions of the parallel model were corroborated in the feature-present condition, in which P3 amplitude was larger when the preceding trial was the opposite of the current trial.

The time course of the sequential effects in the featureabsent condition provided further evidence for the serial search model. Because the serial interpretation posits that the sequential effects for positive trials are due to a modulation of P3 amplitude for the first few negative decisions that typically begin a positive trial, the effects should be present early in the P3 latency range. The sequential effect was indeed evident by $300 \mathrm{msec}$ poststimulus in the feature-absent condition. In addition, if stimulus order af- 
fects the first few negative decisions rather than the searchterminating positive decision, then the sequential effects should be time-locked to the stimulus rather than the response. This prediction was also verified; the sequential effect for positive trials was reversed in the responselocked averages. ${ }^{4}$ Thus, the time course of the sequential effects also supports the serial search model for the feature-absent condition.

\section{Alternative Models}

Four predictions of the serial search model concerning P3 amplitude were verified in the feature-absent condition: (1) P3 amplitude increased with set size for positive trials; (2) there was little $\mathrm{P} 3$ activity on negative trials, especially time-locked to the response; (3) for both positive and negative trials, P3 amplitude was larger when the preceding trial was positive; and (4) the sequential effects were present early in the P3 latency range and were time-locked to the stimulus rather than the response. We will now consider some alternative explanations for these results that would be consistent with parallel search mechanisms.

One possibility is that the mere passage of time is responsible for the effect of set size on $\mathrm{P} 3$ amplitude. As time passes on a given trial without the detection of a target, the subjective probability of detecting a target may decrease. Since larger set sizes are correlated with increased target detection latency, this would result in smaller subjective probabilities and larger P3 amplitudes for larger set sizes. However, if the probability of a positive decision decreases as time passes, then the probability of a negative decision must increase in a complementary fashion. This "time passage"' hypothesis therefore predicts that longer latency negative decisions would be considered more probable, and would thus generate smaller P3 waves for larger set sizes. Since P3 amplitude was small for all negative trials in the feature-absent condition and was not significantly affected by set size, the present data do not support this alternative explanation.

A second alternative explanation is that subjects devote more attention and processing resources to the task for larger set sizes, thereby producing larger P3 waves (cf. Isreal, Wickens, Chesney, \& Donchin, 1980). However, this would predict similar set size effects for both positive and negative trials, whereas P3 amplitude increased with set size only for positive trials in the present experiment.

Additional evidence against these alternative explanations can be adduced from studies in which ERPs were recorded during memory search tasks. For example, if subjects utilize more processing resources for larger set sizes, thus producing larger P3 amplitudes, one would expect that this effect would appear in both memory search and visual search tasks. However, several experiments have shown that P3 amplitude decreases or remains constant as set size increases during memory search (e.g., Ford, Pfefferbaum, Tinlenberg, \& Kopell, 1982; Ford et al., 1979). This result also shows that the mere pas- sage of time does not necessarily lead to larger P3 amplitudes, as discussed above.

The ERP results typically observed during memory search tasks are generally quite different from the present results, and they actually fit quite nicely with the parallel search predictions discussed above. In particular, P3 amplitude is constant or decreases as set size increases during memory search, and it is almost as large for negative trials as for positive trials-a striking contrast to the virtual elimination of the $\mathrm{P} 3$ on negative trials found in the present visual search experiment. These results suggest that memory search is accomplished by a parallel process, a proposal that is consistent with a large body of behavioral data (Hockley, 1984; Ratcliff, 1978; Sternberg, 1975).

Although alternative explanations may be proposed for any one of the P3 effects that were observed in the featureabsent condition, it seems unlikely that a purely parallel search mechanism could account for all of them and also account for the differences between these results and previous studies of memory search. However, all of the results described above were clearly predicted by the serial search model. Thus, although it is impossible to rule out all conceivable parallel models, this experiment provides strong converging evidence for a serial search mechanism.

In addition to supporting feature integration theory, these ERP results are also consistent with several other models of visual perception that incorporate some sort of serial processing. For example, Duncan $(1980,1985)$ has proposed a model in which each item in the stimulus array is identified in parallel, but in which the preidentified items must pass through a limited capacity serial processor in order to reach the response execution stage. The present data cannot distinguish whether the integration of features occurs before or after attention has been focused on an item, and they are therefore compatible with Duncan's model. According to another model (Pashler, 1987), items within small groups are processed in parallel, but only one group is processed at a time (see also Treisman \& Gormican, 1988). If the size of the groups is assumed to be four items or less, then this model is also compatible with the present results (Pashler found that a group size of eight items accounted for his results, but his stimuli consisted of alphanumeric symbols, for which a larger group size might be expected on the basis of familiarity).

\section{Previous ERP Studies of Visual Search}

It seems unlikely that the results of the present experiment would generalize to all visual search tasks. For example, there is significant evidence that alphanumeric stimuli may be identified in parallel (Duncan, 1980; Eriksen \& Spencer, 1969; McClelland \& Rumelhart, 1981; Miller, 1988; Pashler \& Badgio, 1987; Shiffrin \& Gardner, 1972), and the search for such stimuli may produce a very different pattern of P3 amplitude effects. ${ }^{5}$ Indeed, the results of previous ERP studies of visual search that utilized alphanumeric stimuli did not accord with the 
predictions of the serial search model outlined above. For example, Hoffman, Simons, and Houck (1983) found that both positive and negative trials produced large P3 waves, and that P3 amplitude did not increase with set size on positive trials (see also Brookhuis, Mulder, Mulder, \& Gloerich, 1983; Brookhuis et al., 1981; Wijers et al., 1987).

These results, which differ sharply from those of the present experiment, would be expected if a limited capacity parallel mechanism was used to search the alphanumeric stimuli utilized by Hoffman et al. (1983). A parallel search interpretation of their results is also supported by the slope ratio observed for negative as opposed to positive trials, which was $1.4: 1$ rather than the $2: 1$ ratio expected for a serial self-terminating search. A related possibility is that, independently of the fact that Hoffman et al. used alphanumeric stimuli, their set sizes were small enough (2-4 items) to be searched in parallel, in accordance with the molar search model of Pashler (1987).

The different ERP effects might also be related to the fact that Hoffman et al. (1983) used short stimulus durations, which would have disallowed the eye movements that were possible in the present study. There are two ways in which eye movements might have affected the observed pattern of ERP results. First, different search mechanisms may be used when eye movements are present. However, Klein and Farrel (1989) have shown that eye movements have very little effect on visual search performance, which suggests that the present paradigm did not produce a different search strategy simply by allowing eye movements. Second, electrical fields produced by eye movements may be conducted to the EEG electrodes and contaminate the ERP recordings. This would not explain the pattern of results obtained in the present experiment, however: eye movements increased as set size increased, but this effect was observed for both positive and negative trials, and more eye movements occurred on negative trials than on positive trials. Therefore, it seems unlikely that the discrepancy between the present results and those of Hoffman et al. (1983) were a result of eye movements.

\section{Identification of Feature Targets}

According to feature integration theory, the detection of feature-present targets does not require focal attention or target localization (Treisman, 1985; Treisman \& Gelade, 1980). Some other mechanism must therefore be postulated to allow the detection of such targets. In the feature-present condition of the present study, there was an occipitally maximal difference between ERPs elicited by positive as opposed to negative trials, whereas this difference was maximal at parietal sites in the featureabsent condition. This scalp topography difference indicates the existence of separate ERP components with different neuronal generator sources. These generators were active in different proportions for the feature-present and feature-absent conditions, indicating that qualitatively different modes of processing accompany the detection of the two types of targets. Moreover, while the anatomical origin of these components has not yet been determined, the occipital maximum of the target detection wave for the feature-present condition suggests that this component may be generated in the occipital cortex, anatomically prior to the inferotemporal regions that accomplish the identification of complex objects (Haxby et al. 1988; Ungerleider \& Mishkin, 1982). These electrophysiological results are therefore consistent with the claim that feature targets and conjunction targets are detected by different mechanisms.

\section{REFERENCES}

Adam, N., Collins, G. I. (1978). Late components of the visual evoked potential to search in short-term memory. Electroencephalography \& Clinical Neurophysiology, 44, 147-156.

BERGEN, J. R., \& Julesz, B. (1983). Parallel versus serial processing in rapid pattern discrimination. Nature, 303, 696.

Brookhuis, K. A., Mulder, G., Mulder, L. J. M., Gloerich, A. B. M. (1983). The P3 complex as an index of information processing: The effects of response probability. Biological Psychology, 17, 277-296

Brookhuis, K. A., Mulder, G., Mulder, L. J. M., Gloerich, A. B. M., van Dellen, H. J., van der Meere, J. J., EllerMAN, H. H. (1981). Late positive components and stimulus evaluation time. Biological Psychology, 13, 107-123.

Coles, M. G. H., Gratton, G., Bashore, T. R., Eriksen, C. W., \& Donchin, E. (1985). A psychophysiological investigation of the continuous flow model of human information processing. Journal of Experimental Psychology: Human Perception \& Performance, 11, 529-553.

Desmedt, J. E., \& Debecker, J. (1979). Waveform and neural mechanism of the decision P350 elicited without pre-stimulus CNV or readiness potential in random sequences of near-threshold auditory clicks and finger stimuli. Electroencephalography \& Clinical Neurophysiology, 47, 648-670.

Donchin, E., Karis, D., Bashore, T. R., Coles, M. G. H., \& Gratton, G. (1986). Cognitive psychophysiology and human information processing. In M. G. H. Coles, E. Donchin, \& S. W. Porges (Eds.), Psychophysiology: Systems, processes and applications (pp. 244-267). New York: Guilford.

DunCAN, J. (1980). The locus of interference in the perception of simultaneous stimuli. Psychological Review, 87, 272-300.

DunCan, J. (1985). Visual search and selective attention. In M. I. Posner \& O. S. M. Marin (Eds.), Attention and Performance XI (pp. 85-106). Hillsdale, NJ: Erlbaum.

Duncan-Johnson, C. C. (1981). P300 latency: A new metric for information processing. Psychophysiology, 18, 207-215.

Duncan-Johnson, C. C., \& Donchin, E. (1977). On quantifying surprise: The variation of event-related potentials with subjective probability. Psychophysiology, 14, 456-467.

Egeth, H. E., Virzi, R. A., Garbart, H. (1984). Searching for conjunctively defined targets. Joumal of Experimental Psychology: Human Perception \& Performance, 10, 32-39.

ERIKSEN, C. W., \& SPENCER, T. (1969). Rate of information processing in visual perception: Some results and methodological considerations. Journal of Experimental Psychology, 79, 1-16.

FARELL, B. (1984). Attention in the processing of complex visual displays: Detecting features and their combinations. Journal of Experimental Psychology: Human Perception \& Performance, 10, $40-64$.

Ford, J. M., Pfefferbaum, A., Tinlenberg, J. R., Kopell, B. S. (1982). Effects of perceptual and cognitive difficulty on P3 and RT in old and young adults. Electroencephalography \& Clinical Neurophysiology, 54, 311-321. 
Ford, J. M., Roth, W. T., MoHS, R. C., Hopkins, W. F., \& KOPELL, B. S. (1979). Event-related potentials recorded from young and old adults during a memory retrieval task. Electroencephalography \& Clinical Neurophysiology, 47, 450-459.

Glaser, E. M., \& Ruchuin, D. S., (EDS.) (1976). Principles of neurobiological signal analysis. New York: Academic Press.

GOMER, F. E., SPICuzzA, R. J., \& O'DonNELL, R. D. (1976). Evoked potential correlates of visual item recognition during memory-scanning tasks. Physiological Psychology, 4, 61-65.

HANSEN, J. C., \& HillyaRd, S. A. (1988). Temporal dynamics of human auditory selective attention. Psychophysiology, 25, 316-329.

Haxby, J. V., Grady, C. L., Horwitz, B., Schapiro, M. B., Carson, R. E., Ungerleider, L. G., Mishkin, M., HerscoVITCH, P., Friedland, R. P., \& RAPOPORT, S. I. (1988). Mapping two visual pathways in man with regional cerebral blood flow (rCBF) as measured by positron emission tomography (PET) and $\mathrm{H}_{2}^{15 \mathrm{O}}$. Society for Neuroscience Abstracts, 14, 750.

Heinze, H. J., Luck, S. J., Mangun, R., Hillyard, S. A. (1990). Visual event-related potentials index focused attention within bilateral stimulus arrays: I. Evidence for early selection. Electroencephalography \& Clinical Neurophysiology, 75, 511-527.

Hillyard, S. A., \& Kutas, M. (1983). Electrophysiology of cognitive processing. Annual Review of Psychology, 34, 33-61.

Hilly ard, S. A., MünTe, T. F. (1984). Selective attention to color and location: An analysis with event-related brain potentials. Perception \& Psychophysics, 36, 185-198.

HOCKLEY, W. E. (1984). Analysis of response time distributions in the study of cognitive processes. Journal of Experimental Psychology: Leaming, Memory, \& Cognition, 10, 598-615.

Hoffman, J. E., Simons, R. F., Houck, M. R. (1983). Event-related potentials during controlled and automatic target detection. Psychophysiology, 20, 625-632.

Isreal, J. B., Wickens, C. D., Chesney, G. L., \& Donchin, E. (1980). The event-related brain potential as an index of displaymonitoring workload. Human Factors, 22, 211-224.

JENNINGs, J. R., \& WooD, C. C. (1976). The $\epsilon$-adjustment procedure for repeated-measures analyses of variance. Psychophysiology, 13, 277-278.

Johnson, R., JR. (1984). P300: A model of the variables controlling its amplitude. Annals of the New York Academy of Sciences, 425, 223-229.

Johnson, R., JR. (1986). A triarchic model of P300 amplitude. Psychophysiology, 23, 367-384.

JoHNSON, R., JR., \& DONCHIN, E. (1978). On how P300 amplitude varies with the utility of the eliciting stimuli. Electroencephalography \& Clinical Neurophysiology, 44, 424-437.

Johnson, R., JR., \& Donchin, E. (1985). Second thoughts: Multiple P300s elicited by a single stimulus. Psychophysiology, 22, 182-194.

JohNSTON, J. C., \& PASHLER, H. (1988). Feature identification without localization: A reconsideration [Abstract]. Bulletin of the Psychonomic Sociery, 26, 515.

Johnston, V. S., Miller, D. R., \& Burleson, M. H. (1986). Multiple $\mathrm{P} 3 \mathrm{~s}$ to emotional stimuli and their theoretical significance. Psychophysiology, 23, 684-694.

JULESZ, B. (1984). Toward an axiomatic theory of preattentive vision. In G. Edelman, M. Cowan, \& M. D. Gall (Eds.), Dynamic aspects of neocortical function (pp. 120-148). New York: Wiley.

KleIN, R., \& FARRELL, M. (1989). Search performance without eye movements. Perception \& Psychophysics, 46, 476-482.

KutAs, M., \& Donchin, E. (1978). Variations in the latency of P300 as a function of variations in semantic categorization. In D. Otto (Ed.), New perspectives in event-related potential research (pp. 198-201). Washington, DC: U.S. Environmental Protection Agency.

Kutas, M., McCarThy, G., \&onChIN, E. (1977). Augmenting mental chronometry: The $\mathrm{P} 300$ as a measure of stimulus evaluation time. Science, 197, 792-795.

Luck, S. J., Heinze, H. J., Mangun, G. R., \& Hillyard, S. A. (1990). Visual event-related potentials index focused attention within bilateral stimulus arrays: II. Functional dissociation of P1 and N1 components. Electroencephalography \& Clinical Neurophysiology, 75, 528-542.

LuCK, S. J., Hillyard, S. A. (1988). Event-related potentials to visual "pop-out" stimuli. Society for Neuroscience Abstracts, 14, 1013

Magliero, A., Bashore, T. R., Coles, M. G. H., \& Donchin, E. (1984). On the dependence of P300 latency on stimulus evaluation processes. Psychophysiology, 21, 171-186.

MARR, D. (1982). Vision: A computational investigation into the human representation and processing of visual information. San Francisco: W. H. Freeman.

MCCARThy, G., Donchin, E. (1981). A metric for thought: A comparison of P300 latency and reaction time. Science, 211, 77-79.

MCClelland, J. L., \& Rumelhart, D. E. (1981). An interactive activation model of context effects in letter perception: Part 1. An account of basic findings. Psychological Review, 88, 375-407.

Michalewski, H. J., Patterson, J. V., Pratt, H., Barret, G., \& STARR, A. (1988). Memory scanning and event-related potentials. Psychophysiology, 25, 469-470.

MILLER, J. (1988). Components of the location probability effect in visual search tasks. Journal of Experimental Psychology: Human Perception \& Performance, 14, 453-471.

Nakayama, K., \& Silverman, G. H. (1986). Serial and parallel processing of visual feature conjunctions. Nature, 320, 264-265.

NeISSER, U., (ED.) (1967). Cognitive psychology. New York: AppletonCentury-Crofts.

Osman, A., Bashore, T. R., Coles, M. G. H., Donchin, E., \& MEYER, D. E. (1988). A psychophysiological study of response preparation based on partial information. Psychophysiology, 25, 426.

PAshler, H. (1987). Detecting conjunctions of color and form: Reassessing the serial search hypothesis. Perception \& Psychophysics, 41, 191-201.

PAshler, H., \& BADgio, P. C. (1985). Visual attention and stimulus identification. Journal of Experimental Psychology: Human Perception \& Peformance, 11, 105-121.

Pashler, H., Badgio, P. C. (1987). Attentional issues in the identification of alphanumeric characters. In M. Coltheart (Ed.), Attention and Performance XII (pp. 63-81). Hillsdale, NJ: Erlbaum.

PAUL, D., \& SuTton, S. (1972). Evoked potential correlates of response criterion in auditory signal detection. Science, 177, 362-364.

Ratcliff, R. (1978). A theory of memory retrieval. Psychological Review, 85, 59-108.

ShIFFRIN, R. M., \& GARDNER, G. T. (1972). Visual processing capacity and attentional control. Journal of Experimental Psychology, 93, $72-83$.

Squires, K. [C]., Petuchowski, S., Wickens, C., \& Donchin, E. (1977). The effects of stimulus sequence on event related potentials: A comparison of visual and auditory sequences. Perception \& Psychophysics, 22, 31-40.

SQuires, K. C., Squires, N. K., \& Hillyard, S. A. (1975). Decisionrelated cortical potentials during an auditory signal detection task with cued observation intervals. Joumal of Experimental Psychology: $\mathrm{Hu}$ man Perception \& Performance, 103, 268-279.

Squires, K. C., Wickens, C., SQuires, N. K., \& Donchin, E. (1976). The effect of stimulus sequence on the waveform of the cortical eventrelated potential. Science, 193, 1142-1146.

SternberG, S. (1975). Memory scanning: New findings and current controversies. Quarterly Journal of Experimental Psychology, 27, 1-32.

STuss, D. T., \& Picron, T. W. (1978). Neurophysiological correlates of human concept formation. Behavioral Biology, 23, 135-162.

Treisman, A. (1985). Preattentive processing in vision. Computer Vision, Graphics, \& Image Processing, 31, 156-177.

Treisman, A., \& Gelade, G. (1980). A feature-integration theory of attention. Cognitive Psychology, 12, 97-136.

Treisman, A., \& Gormican, S. (1988). Feature analysis in early vision: Evidence from search asymmetries. Psychological Review, 95, 15-48. Treisman, A., \& Paterson, R. (1984). Emergent features, attention, 
and object perception. Journal of Experimental Psychology: Human Perception \& Performance, 10, 12-31.

Treisman, A., \& Souther, J. (1985). Search asymmetry: A diagnostic for preattentive processing of separable features. Journal of Experimental Psychology: General, 114, 285-310.

Ullman, S. (1984). Visual routines. Cognition, 18, 97-159.

UNGerleider, L. G., Mishkin, M. (1982). Two cortical visual systems. In D. J. Ingle, R. J. W. Mansfield, \& M. A. Goodale (Eds.), The analysis of visual behavior (pp. 549-586). Cambridge, MA: MIT Press.

Vieira, A., \& Treisman, A. (1988). Automatic search: Changing perceptions or procedures [Abstract]. Bulletin of the Psychonomic Society, 26, 515.

Wijers, A. A., Mulder, G., Okita, T., Mulder, L. J. M., \& SCHEFFERS, M. K. (1989). Attention to color: An analysis of selection, controlled search, and motor activation, using event-related potentials. Psychophysiology, 26, 89-109.

Wijers, A. A., Okita, T., Mulder, G., Mulder, L. J. M., Lorist, M. M., Polesz, R., \& Scheffers, M. K. (1987). Visual search and spatial attention: ERPs in focussed and divided attention conditions. Biological Psychology, 25, 33-60.

Wolfe, J. M., CAve, K. R., Franzel, S. L. (1989). Guided search: An alternative to the feature integration model for visual search. Journal of Experimental Psychology: Human Perception \& Performance, 15, 419-433.

Wolfe, J. M., Franzel, S. L. (1988). Binocularity and visual search. Perception \& Psychophysics, 44, $81-93$.

Woods, D. L., Courchesne, E., Hillyard, S. A., \& Galambos, R. (1980). Split-second recovery of the P3 component in multiple decision tasks. In H. H. Kornhuber \& L. Deecke (Eds.), Motivation, motor, and sensory processes of the brain: Progress in brain research (Vol. 54, pp. 322-330). Amsterdam: Elsevier/North-Holland.

Woody, C. D. (1967). Characterization of an adaptive filter for the analysis of variable latency neuroelectric signals. Medical \& Biological Engineering, 5, 539-553.

\section{NOTES}

1. This paradigm was chosen instead of the more common conjunctionsearch versus feature-search paradigm, for two reasons. First, serial and parallel search modes can be produced with identical stimulus items by simply reversing target and distractor identities, and this partially controls for changes in the ERPs due to physical stimulus differences. Second, if conjunction targets are used to produce serial search, subjects may learn to utilize feature-specific filter mechanisms, thereby accomplishing a parallel search (Egeth et al., 1984; Wolfe, Cave, \& Franzel, 1989). Whether conjunction targets or feature-absent targets are used, however, feature integration theory predicts the same sort of serial, selfterminating search process.

2. Since there was little P3 activity on the negative, feature-absent trials, the flat slope of the set size function for this measure should be viewed as indicating a lack of measurable P3 activity, rather than a lack of change in the duration of the cognitive processes indexed by P3.

3. It is conceivable, however, that additional processes may be interposed between the identification of a target item and the categorization of the entire stimulus array as a member of the target class. Since P3 latency might be sensitive to variations in the duration of such processes, we cannot completely rule out the possibility that the effects of set size are mediated in part by postperceptual, but precategorization, processes. Nonetheless, it is difficult to imagine a process occurring between target identification and stimulus categorization that would increase in duration linearly with the number of distractor items and produce a precise 2:1 ratio of slopes for negative as opposed to positive trials.

4. The reversed sequential effect for the response-locked averages can also be explained by local probabilities: The response-locked P3 activity on positive trials was due to the final, positive decision, and it was therefore smaller when the preceding trial also contained a positive decision.

5. It should be noted that a parallel search for alphanumeric stimuli is not necessarily inconsistent with feature integration theory. Treisman and her colleagues have proposed that items such as alphanumeric characters may be processed as features after extensive experience (cf. Treisman \& Paterson, 1984; Vieira \& Treisman, 1988).

(Manuscript received April 28, 1989; revision accepted for publication June 9,1990 .)

\section{Erratum}

F. L. Kitterle, S. Christman, \& J. B. Hellige. Hemispheric differences are found in the identification, but not the detection, of low versus high spatial frequencies. Perception \& Psychophysics, $1990,48(4), 297-306-(1)$ On page 300, the last phrase of the third sentence under the heading "Reaction time data" should read "... although there is some suggestion that there are slightly faster RTs with LVF [rather than RVF] stimuli." (2) On page 305, in the Methods section of Experiment 5 , the second sentence under "Stimuli" should read "The contrast of the gratings was .1 , and the..." 